\title{
Mesenchymal stem cells and regenerative medicine: how lipogems technology make them easy, safe and more effective to use
}

\begin{abstract}
Lipogems ${ }^{\circledR}$ was designed to harvest, process and inject aspirated fat tissue which is washed, emulsified and rinsed, while adipose cluster dimensions are gradually reduced in a completely closed device by only mechanical forces. Lipogems ${ }^{\circledR}$ tissue product represents a natural implantable bioreactor that incorporates the main ele-ments for a perfect natural regenerative response: the Scaffold (the adipose tissue structure), the Cells (Pericytes/MSCs), and the Grow factors (secreted cytokines and chemokines).

The local injection of such a tissue is a living graft, which can work for long time enhancing the natural local healing potential. It has been used safely and effectively in thousands of patients, in human and veterinary medicine in many different clinical applications. The device has obtained general FDA clearance in 2014 and in 2016 for specific arthroscopic use. The purpose of this short review is to present the concepts of Lipogems ${ }^{\circledR}$ technology and an update in bibliography so that whoever is interested can easily search for more information. Figures and videos are easily available on google search so have not been added to this review.
\end{abstract}

Volume 2 Issue 2 - 2017

\author{
Carlo Tremolada \\ Image institute, Italy
}

Correspondence: Carlo Tremolada, Image institute, Italy, Email carlo.tremolada@gmail.com

Received: August 17, 2017 | Published: November 10, 2017

\section{Adipose tissue as the Ideal Mscs source}

MSCs are found as pericytes in all capillaries of all tissues of our body and the concept that fat tissue is an optimal source is now well established..$^{1-5}$ MSC of fat (ASCs) are very numerous compared to other tissues. ${ }^{4-8}$ Fat tissue is available in most patients and can be easily harvested with a minimally invasive surgical approach, using a blunt cannula and syringe vacuum, offering a highly viable ASC population with optimal differentiation potential that is maintained with aging., ${ }^{3,9-12}$ These cells can differentiate in vitro into several cell lineages, such as adipocytes, chondrocytes, osteoblasts, and myoblasts..$^{2-5,13-19}$ In addition, they naturally secrete many bioactive molecules working as a sort of "mini-drugstore" that modulates the local immune response and creates an ideal regenerative environment. ${ }^{20-23}$ The use of ASCs, expanded or simply obtained by enzymatic treatment as SVF (Stromal Vascu-lar Fraction), created a huge interest and both in vitro and in vivo studies clearly demonstrated their anti-inflammatory and regenerative potentials 24 . Nevertheless, the prolonged ex vivo expansion may in-duce cell senescence, thus leading to clinical results below expectations. In addition, the majority of the proposed techniques have complex regulatory issues. ${ }^{25-29}$ In the last few years, we have been facing a significant number of studies aimed at the improvement of the therapeutic effects provided by the traditional fat transfer and structural fat grafting techniques. ${ }^{30-33}$ In an effort to optimize this regenerative potential, MSC enrichment techniques, essentially based on enzymatic or mechanical devices, have been proposed. ${ }^{34,35}$ In our experience, a minimally manipulated fat tissue is preferable, not only from a regulatory prospective, ${ }^{28,29}$ but mainly because of the biological rationale. Indeed, mechanically derived MSC versus enzymatically isolated MSC have shown to have better differentiation potentia19, 10, wider secretome36, and a large difference in exosomes contents. ${ }^{22,37,38}$ The Lipogems ${ }^{\circledR}$ technology guarantees all of the requirements in an easy, quick, disposable device and represents a very promising "natural" approach in different fields..$^{9,39-51}$

\section{The Lipogems $®$ system}

The Lipogems ${ }^{\circledR}$ system incorporates a new technology to harvest, process and transfer adipose tissue. The technical part of the procedure is well described both in journal articles ${ }^{9,32,52}$ and in the web (https:// www.youtube.com/results? search_query=Lipogems+system). The resulting product is com-posed of small intact adipose tissue clusters (250-650 microns) and contains pericytes retained within an intact stromal vascular niche. It is now well established that cells defined as MSCs exhibit perivascular location and pericyte identity in vivo53-55. Pericytes are structural cells embracing the external wall of the microvessels and capillaries of the stromal vascular fraction of fat tissue and, after an injury such as inflammation or a damage of the vascular wall, they detach from the capillaries and gradually convert into activated regenerative MSCs. ${ }^{21,53,54}$ Such pericyte-to-MSC activation entails the release (through exosomes) of regenerative factors and bioactive molecules which would make the transplanted Lipogems ${ }^{\circledR}$ product acting as a "personalized drugstore"56. The exquisite balance between angiogenetic, antiinflammatory, immunomodulatory, anti-apoptotic, anti-microbial, mitotic, anti-scarring properties of MSCs allows a completely natural tissue repair and regeneration 36 . The second main characteristic of Lipogems ${ }^{\circledR}$ is related to the time-advantage. Indeed, the gentle mechanical method allows obtaining a ready-to-use product in less than 20 minutes compared to the sev-eral hours, days or weeks required for the enzymatic digestion of the lipoaspirate and eventual in vitro cell expansion with substantial delay in the clinical application. In addition, Lipogems ${ }^{\circledR}$ is minimally manipulated according to the regulations set forth by the FDA. It received the FDA clearance as a class II medical device for processing autologous adipose tissue (510(k) first approval in US in December 2014 and new clearance in November 2016 for arthroscopic applications. The reduction of adipose cluster dimensions from $2-4,5 \mathrm{~mm}$ before processing to $0,3-$ $0,7 \mathrm{~mm}$ of the fi-nal product, maintaining a perfect structural integrity, improves its ease of handling and post-transplant engraftment, due 
to the more effective and faster graft revascularization. Several new promising fields of application are reported every month as this technique is spreading all over the world and have already received regulatory approval in 23 countries (http://www.lipogems.eu/indexeng.html).

\section{Clinical applications of lipogems}

Lipogems has been shown to be safe and seems to work clinically much better than enzymatically iso-lated MSCs (both SVF or cultivated) as the preserved niche within a natural adipose scaffold works as the ideal "functional unit". ${ }^{21,36}$ In general surgery, Lipogems ${ }^{\circledR}$ has been used as a valid approach for the treatment of fecal incontinence and anal fistulas, showing impressive long term real morphological regeneration of muscle and neurological function. ${ }^{41,43,49,57}$ In oncology, Lipogems ${ }^{\circledR}$ has been proved useful when injected in atrophied tissue after radiotherapy 58. The regenerative potential in musculoskeletal diseases is impressive and more extended clinical trials are currently performed worldwide to confirm the first outstanding results. ${ }^{42,46,48,50}$ In orthopedic surgery, most patients with joint degenerative and inflammatory diseases may benefit of Lipogems ${ }^{\circledR}$ intra and peri-articular injection. ${ }^{59,60}$ After injection of a variable quantity of Lipogems ${ }^{\circledR}$ (2-12 $\mathrm{ml}$ depending from the joint), patients generally reported a brilliant immediate improvement of symptoms with long-term pain resolution. In many cases, patients previously candidate for surgery, no longer needed it because of the complete or substantial resolution of their symptoms. Preoperative and post-operative X-ray and MRI comparison showed a possible regeneration of the articular cartilage and a widening of the joint space 6 to 18 months after treatment. Moreover, the orthopedic use Lipogems ${ }^{\circledR}$ has also proved to be rewarding to foster repair in injured ligaments or tendons, in meniscal lesions, around surgical wounds, inside and around osteoto my gaps. These finding have been confirmed in Vet-erinary Medicine where Lipogems is becoming the leading regenerative therapy in polo horses and dog. ${ }^{61}$

In plastic reconstructive surgery, Lipogems ${ }^{\circledR}$ helps the healing of chronic ulceration of the inferior legs and feet, above all in diabetic patients, with encouraging results. Only the vasculogenic properties of MSCs can explain these successes. ${ }^{62,63}$ The aesthetic surgery is a growing field of application. Lipogems ${ }^{\circledR}$ is used alone or in association with traditional surgical techniques such as facelift, blepharoplasty, breast augmentation and others. In the latter case, Lipogems ${ }^{\circledR}$ improves and accelerates wound healing and improves skin texture. Optimal re-sults have been obtained in the periorbital area. After surgical intervention, the patients complain no pain, swelling or bruising, and are generally greatly satisfied. This treatment is often extended in a full-face bio-restoration aimed to define face contour, give it tone, new brightness and uniformity64. A re-cent publication describes the use of Lipogems ${ }^{\circledR}$ during orthognathic surgery in 120 patients who un-derwent a double jaw intervention. Lipogems ${ }^{\circledR}$ was injected in multiple tissue planes and tunnels where the soft tissue lack had to be restored (mid face and mandible contours, neck, lips, chin profile). Results were compared to a series of patients treated with a traditional lipofilling technique. All the patients, except for 2 , showed better enhancement of face morphology and skin texture, and much less post-operative swelling with consequently faster recovery. ${ }^{45}$

\section{Lipogems and future horizons of regenerative medicine}

Fat tissue transfer is a well established autologous method which has several clinical applications. The Lipogems ${ }^{\circledR}$ technology has been created to improve traditional grafting technique. ${ }^{9}$ The most important and attractive feature of Lipogems ${ }^{\circledR}$ technology, and in general of MSCs, is the ability to naturally repair and regenerate certain types of tissue, such as joint cartilage, representing an ideal scaffold 40 . Recently, it has been demonstrated that exposure of Lipogems-derived MSCs to properly conveyed radio-electric fields was able to optimize stem cell expression of multipotency and lineage commitment at a remarkably higher degree than in enzymatically-dissociated MSCs obtained from the same donors65. This finding may significantly improve future cell therapy efforts66. Lipogems ${ }^{\circledR}$ technology fulfils the requirement to overcome the current limitations related to in vitro fat manipulation, making MSCs easily available within their natural 3D scaffold for immediate clinical use. It must be stressed that IFATS (International Federation for Adipose Therapeutics and Science) and ISCT (International Society for Cellular Therapy) recently established some clear definitions of Stromal Vascular Fraction and adiposederived mesenchymal stem cells to better manage the future trials and to allows multicenter comparative studies. ${ }^{1,67,68}$ We strongly believe that many of these trials should be compared to Lipogems ${ }^{\circledR}$ safety and effectiveness.

\section{Conclusion}

Adipose tissue is the ideal source for extracting but above all for using MSCs since (i) it can be easily accessed and harvested via a minimally invasive surgical procedure, (ii) it can be found in sufficient quantities in most people and (iii) it guarantees an adequate amount of progenitor cells with a good vi-ability and minimally agerelated differentiating potential. The Lipogems ${ }^{\circledR}$ technology naturally optimizes fat tissue healing properties. Without using enzymes, additives or centrifugations, but relying upon the use of mild mechanical forces, the Lipogems ${ }^{\circledR}$ system yields a micro-fragmented product that rescue damaged tissues with a regenerative environment for a long time. A number of randomized and controlled studies are now ongoing to strengthen its critical analysis and further develop and accelerate innovative therapeutic strategies and clinical protocols.

\section{Acknowledgements}

None.

\section{Conflict of interest}

Carlo Tremolada is the president and founder of Lipogems company.

\section{References}

1. Bourin P, Bunnell BA, Casteilla L, et al. Stromal cells from the adipose tissue-derived stromal vascular fraction and culture expanded adipose tissue-derived stromal/stem cells: a joint statement of the International Federation for Adipose Therapeutics and Science (IFATS) and the International Society for Cellular Therapy (ISCT). Cytotherapy. 2013;15(6):641-648

2. Jeon YJ, Kim J, Cho JH, et al. Comparative analysis of human mesenchymal stem cells derived from bone marrow, placenta, and adipose tissue as sources of cell therapy. J Cell Biochem. 2016;117(5):1112-1125.

3. Strem BM, Hicok KC, Zhu M, et al. Multipotential differentiation of adipose tissue-derived stem cells. Keio J Med. 2005;54(3):132-141.

4. Zuk PA, Zhu M, Ashjian P, et al. Human adipose tissue is a source of multipotent stem cells. Mol Biol Cel. 2002;13(12):4279-4295.

5. Zuk PA, Zhu M, Mizuno H, et al. Multilineage cells from human adipose tissue: implications for cell-based therapies. Tissue Eng. 2001;7(2):211228 . 
6. De Ugarte DA, Morizono K, Elbarbary A, et al. Comparison of multi-lineage cells from human adipose tissue and bone marrow. Cells Tissues organs. 2003;174(3):101-109.

7. Gimble JM, Bunnell BA, Chiu ES, et al. Concise review: Adipose-derived stromal vascular fraction cells and stem cells: Let's not get lost in translation. Stem Cells. 2011;29(5):749-754.

8. Lin G, Garcia M, Ning H, et al. Defining stem and progenitor cells within adipose tissue. Stem Cells Dev. 2008;17(6):1053-1063.

9. Bianchi F, Maioli M, Leonardi E, et al. A new nonenzymatic method and device to obtain a fat tissue derivative highly enriched in pericyte-like elements by mild mechanical forces from human lipoaspirates. Cell transplantation. 2013;22(11):2063-2077.

10. Carelli S, Messaggio F, Canazza A, et al. Characteristics and properties of mesenchymal stem cells derived from microfragmented adipose tissue. Cell Transplant. 2015;24(7):1233-1252.

11. Stolzing A, Jones E, McGonagle D, et al. Age-related changes in human bone marrow-derived mesenchymal stem cells: consequences for cell therapies. Mech Ageing Dev. 2008;129(3):163-173.

12. Von Heimburg D, Hemmrich K, Haydarlioglu S, et al. Comparison of viable cell yield from excised versus aspirated adipose tissue. Cells Tissues Organs. 2004;178(2):87-92.

13. Cao Y, Sun Z, Liao L, et al. Human adipose tissue-derived stem cells differentiate into endothelial cells in vitro and improve postnatal neovascularization in vivo. Biochemical and biophysical research communications. 2005;332(2):370-379.

14. Caplan AI. Mesenchymal stem cells. Journal of orthopaedic research 1991;9(5):641-650.

15. Erickson GR, Gimble JM, Franklin DM, et al. Chondrogenic potential of adipose tissue-derived stromal cells in vitro and in vivo. Biochemical and biophysical research communications. 2002;290(2):763-769.

16. Fraser JK, Schreiber R, Strem B, et al. Plasticity of human adipose stem cells toward endothelial cells and cardiomyocytes. Nat Clin Pract Cardiovasc Med. 2006;3:33-S37.

17. Halvorsen Y, Wilkison W, Gimble J. Adipose-derived stromal cells--thei utility and potential in bone formation. Int J Obes Relat Metab Disord. 2000;24(S4):S41-S44

18. Halvorsen Y-DC, Franklin D, Bond AL, et al. Extracellular matrix mineralization and osteoblast gene expression by human adipose tissue-derived stromal cells. Tissue Eng. 2001;7(6):729-741.

19. Ren H, Sang Y, Zhang F, et al. Comparative analysis of human mesenchymal stem cells from umbilical cord, dental pulp, and menstrual blood as sources for cell therapy. Stem cells international. 2016;7(6):729-741.

20. Caplan AI. Adult mesenchymal stem cells for tissue engineering versus regenerative medicine. Journal of cellular physiology. 2007;213(2):341347.

21. Caplan AI, Dennis JE. Mesenchymal stem cells as trophic mediators. $J$ Cell Biochem. 2006;98(5):1076-1084.

22. Rani S, Ryan AE, Griffin MD, et al. Mesenchymal stem cell-derived extracellular vesicles: toward cell-free therapeutic applications. Mol Ther 2015;23(5):812-823

23. Somoza RA, Correa D, Caplan AI Roles for mesenchymal stem cells as medicinal signaling cells

24. Chamberlain G, Fox J, Ashton B, et al. Concise review: mesenchyma stem cells: their phenotype, differentiation capacity, immunological features, and potential for homing. Stem cells. 2007;25(11):2739-2749.
25. Ährlund-Richter L, De Luca M, Marshak DR, et al. Isolation and production of cells suitable for human therapy: challenges ahead. Cell Stem Cell. 2009;4(1):20-26.

26. Arcidiacono JA, Blair JW, Benton KA. US Food and Drug Administration international collaborations for cellular therapy product regulation. Stem Cell Res Ther. 2012;3(5):38.

27. Sensebé L, Bourin P, Tarte K. Good manufacturing practices production of mesenchymal stem/stromal cells. Human gene therapy. 2010;22(1):19-26

28. Riis S, Zachar V, Boucher S, et al. Critical steps in the isolation and expansion of adipose-derived stem cells for translational therapy. Expert Rev Mol Med. 2015;17:e11.

29. Roseti L, Serra M, Tigani D, et al. Cell manipulation in autologous chondrocyte implantation: from research to cleanroom. La Chirurgia degli organi di movimento. 2008;91(3):147-151.

30. Coleman SR. Structural Fat Grafting. Plastic and Reconstructive Surgery. 2005;115(6):1777-1778.

31. Coleman SR. Structural fat grafting: more than a permanent filler. Plast Reconstr Surg. 2006;118(3S):108S-120.

32. Tremolada C, Colombo V, Ventura C. Adipose Tissue and Mesenchymal Stem Cells: State of the Art and Lipogems ${ }^{\circledR}$ Technology Development Curr Stem Cell Rep. 2016;2(3):304-312.

33. Alexander R. Autologous fat grafts as mesenchymal stromal stem cell source for use in prolotherapy: a simple technique to acquire lipoaspirants. Journal of Prolotherapy. 2011;3(3):680-8.

34. Dongen JA, Tuin AJ, Spiekman M, et al. Comparison of intraoperative procedures for isolation of clinical grade stromal vascular fraction for regenerative purposes: a systematic review. J Tissue Eng Regen Med 2017.

35. Oberbauer E, Steffenhagen C, Wurzer C, et al. Enzymatic and non-enzymatic isolation systems for adipose tissue-derived cells: current state of the art. Cell Regen (Lond). 2015;4(1):7.

36. Coronado R, Krutchkoff B, Cormier M, et al. Characterization and differentiation of human adipose derived stem cells isolated non enzymatically from micro-fractured fat obtained with a commercially available kit ( $\mathrm{Li}$ pogems). Ifats San Diego 2016 Conference; USA: IEEE; 2016

37. García-Contreras M, Messaggio F, Jimenez O, et al. Differences in exosome content of human adipose tissue processed by non-enzymatic and enzymatic methods. Cell R4. 2015;3(1):e1423.

38. Yu B, Zhang X, Li X. Exosomes derived from mesenchymal stem cells Int J Mol Sci. 2014;15(3):4142-4157.

39. Benzi R, Marfia G, Bosetti M, et al. Microfractured lipoaspirate may help oral bone and soft tissue regeneration: a case report. Cell $R 4$. 2015;3(3):e1583

40. Bosetti M, Borrone A, Follenzi A, et al. Human lipoaspirate as autologous injectable active scaffold for one-step repair of cartilage defects. Cell transplant. 2016;25(6):1043-1056.

41. Cestaro G, De Rosa M, Massa S, et al. Intersphincteric anal lipofilling with micro-fragmented fat tissue for the treatment of faecal incontinence: preliminary results of three patients. Wideochir Inne Tech Maloinwazyjne. 2015;10(2):337-341.

42. Franceschini M, Castellaneta C, Mineo G. Injection of autologous micro-fragmented adipose tissue for the treatment of post traumatic degenerative lesion of knee cartilage: a case report. CellR4. 2016.

43. Giori A, Tremolada C, Vailati R, et al. Recovery of function in anal incontinence after micro-fragmented fat graft (Lipogems $\left.{ }^{\circledR}\right)$ injection: two years follow up of the first 5 cases. CellR4. 2015;3(2):e1544. 
44. Grossi P, Giarratana S, Cernei S, et al. Low back pain treated with disc decompression and autologous micro-fragmented adipose tissue: a case report. CellR4. 2016

45. Raffaini M, Tremolada C. Micro fractured and purified adipose tissue graft (Lipogems $\left.{ }^{\circledR}\right)$ can improve the orthognathic surgery outcomes both aesthetically and in postoperative healing. CellR4. 2014;2(0):e1118.

46. Randelli P, Menon A, Ragone V, et al. Lipogems product treatment increases the proliferation rate of human tendon stem cells without affecting their stemness and differentiation capability. Stem cells international; 2016.

47. Saibene A, Pipolo C, Lorusso R, et al. Transnasal endoscopic microfractured fat injection in glottic insufficiency. B-ENT. 2015;11(3):229-234.

48. Striano R, Chen H, Bilbool N, et al. Non-responsive knee pain with osteoarthritis and concurrent meniscal disease treated with autologous micro-fragmented adipose tissue under continuous ultrasound guidance. Cell R4. 2015;3(5):e1690.

49. Testa A, Verdi A, Termini L. New frontiers of the treatment of perianal fistulas: the autologous transplantation of stem cells adult multipoten cells derived from human adipose tissue. $6^{\text {th }}$ National Congress of the Italian Society of ColoRectal Surgery Patients First: Quality of Care, Management, Multidisciplinary Approach; 2015.

50. Tremolada C, Beltrami G, Magri A, et al. Adipose mesenchymal stem cells and "regenerative adipose tissue graft"(Lipogems $\left.{ }^{\circledR}\right)$ for musculoskeletal re generation. Eur J Musculoskelet Dis. 2014;3(2):57-67.

51. Tremolada C, Palmieri G, Ricordi C. Adipocyte transplantation and stem cells: plastic surgery meets regenerative medicine. Cell transplantation 2010;19(10):1217-1223.

52. Tremolada C. Device and method for preparing tissue, particularly adipose tissue. Google Patents; 2015.

53. Caplan AI. All MSCs are pericytes? Cell stem cell. 2008;3(3):229-230.

54. Crisan M, Yap S, Casteilla L, et al. A perivascular origin for mesenchymal stem cells in multiple human organs. Cell stem cell. 2008;3(3):301-313.

55. Da Silva Meirelles L, Caplan AI, et al. In search of the in vivo identity of mesenchymal stem cells. Stem cells. 208;26(9):2287-2299.

56. Caplan AI, Correa D. The MSC: an injury drugstore. Cell stem cell. 2011;9(1):11-15.
57. Nudo R, Bianchini G, De Villa F, et al. Role of lipofilling with Lipogems ${ }^{\circledR}$ device in the treatment of anal fistulas - my personal experience. $14^{\circ}$ International Coloproctology Meeting - SICCR 2016.

58. Tremolada C. Autologous Cell-Therapy with Lipogems. $13^{\text {th }}$ Annual cellbased therapies \& tissue engineering; May 12-14, 2014; 2014.

59. Russo A, Condello V, Madonna V, et al. Two years experience with Lipogems ${ }^{\circledR}$ system: our indications and results, Sigascot; 2016.

60. Slynarski K. LIPOGEMS $®$ injections for the treatment of knee chondropathy: two years follow up. ICRS. 2016;2016:22.

61. Zeira O. Autologous micro-fragmented adipose tissue in dogs with arthropaties: safety, feasibility and clinical outcome. Ifats San Diego 2016 Conference; 2016

62. Ceserani V, Ferri A, Berenzi A, et al. Angiogenic and anti-inflammatory properties of micro-fragmented fat tissue and its derived mesenchymal stromal cells. Vasc Cell. 2016;8(1):3.

63. Del Papa N, Di Luca G, Sambataro D, et al. Regional implantation of autologous adipose tissue-derived cells induces a prompt healing of long-lasting indolent digital ulcers in patients with systemic sclerosis. Cell transplantation. 2015;24(11):2297-2305.

64. Kao C. The use of micro fractured fat for grafting of the periorbital region: 46 consecutive cases. IFATS New Orleans 2015 Conference $-13^{\text {th }}$ Annual IFATS Meeting, USA: Springer; 2015.

65. Maioli M, Rinaldi S, Santaniello S, et al. Radioelectric asymmetric conveyed fields and human adipose-derived stem cells obtained with a nonenzymatic method and device: a novel approach to multipotency. Cell Transplant. 2014;23(12):1489-500.

66. Ventura C, Bianchi F, Cavallini C, et al. The use of physical energy for tissue healing. Eur Heart J. 2015;Suppl 17(Suppl A):A69-73.

67. Magalon J, Daumas A, Veran J, et al. Autologous adipose tissue-derived cells: are we talking about adipose derived stem cells, stromal vascular fraction, or coleman fat grafting? Cell Transplant. 2015;24(12):26672668 .

68. Zhao Y, Betzler C, Popp F, et al. Fair or foul: time for standard protocols for potential application of adipose-derived stem cells. J Stem Cell Res Ther. 2014;4(220):2. 